Fourth International Conference on Sustainable Construction Materials and Technologies http://www.claisse.info/Proceedings.htm

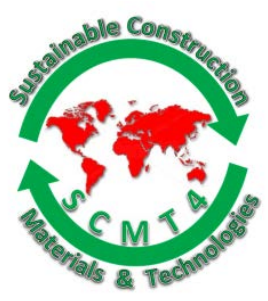

SCMT4

Las Vegas, USA, August 7-11, 2016

\title{
Freeze-Thaw Durability of Soil Stabilized with Class C Fly Ash and Cement Kiln Dust
}

\author{
Pranshoo Solanki ${ }^{1 a}$, and Bastian Hauk-Jegen ${ }^{1 b}$ \\ ${ }^{1}$ College of Applied Science and Technology, Illinois State University, Campus Box 5100, Normal, IL, \\ USA. ${ }^{1 a}$ Email: <psolanki@ilstu.edu>, ${ }^{1 b}$ Email: <bhaukje@ilstu.edu>.
}

\begin{abstract}
This study examined the freeze-thaw (F-T) durability of soils stabilized by using class C fly ash (CFA) and cement kiln dust (CKD). A total of two soils, namely Carnasaw (fat clay) and Lomill (fat clay) series, were utilized. The laboratory procedure included evaluation of unconfined compressive strength (UCS) and resilient modulus $\left(\mathrm{M}_{\mathrm{r}}\right)$ at the end of conventional F-T cycles. The results indicated that UCS or $\mathrm{M}_{\mathrm{r}}$ of all the specimens decreased at the end of F-T cycles. The UCS values of both raw and stabilized soil specimens were found to decrease with an increase in the number of F-T cycles. The level of reduction in the UCS values was influenced by the type of soil and type and amount of stabilizing agent. A major loss in strength was observed between 0 and 1 F-T cycle. Soil specimens stabilized with CKD offered maximum resistance towards F-T cycles. Selected specimens tested for size effect showed that UCS values of bigger size specimens was lower than the UCS values of corresponding specimens having smaller size.
\end{abstract}

\section{INTRODUCTION}

The demand for pavement networks in the United States is greater than ever, and the conditions of existing roadways are worsening due to heavier vehicles and increased volume. According to the recent report by AASHTO/TRIP, only 31 percent of the nation's major roads are in good condition (TRIP, 2015). This report found that 28 percent of the nation's major urban roads have pavements that are in substandard or poor condition and provide an unacceptably rough ride to motorists. Weak subgrade soils are a leading factor in this regard. In the last few decades, pavement engineers have been challenged to build, repair and maintain pavement systems with enhanced longevity and reduced costs. Specifically, efforts have been made to improve the design methodology (AASHTO, 2004) and to establish techniques for modification of highway pavement materials. Soil properties are often improved through the chemical stabilization; it enhances the engineering properties of subgrade soils, which is essential for structurally sound pavements. With rising cost of traditional stabilizers such as lime, cement and asphalt, highway agencies often use industrial by-products such as class C fly ash (CFA) and cement kiln dust (CKD) for soil stabilization.

Previous studies on soil stabilization using CFA and CKD have demonstrated the benefit of their usage in building stable subgrade foundation for pavement. However, the effect of freeze-thaw (F-T) conditions, 
referred to as “durability” (or long-term performance), is not frequently addressed. Also, detrimental effects of climatic conditions (F-T) on our national pavement infrastructure have been highlighted by AASHTO and NCHRP reports (Wen et al., 2014; AASHTO/TRIP, 2015). Knowledge about the freezethaw durability of soils stabilized with CFA and CKD is expected to be helpful in the development of rational design procedures for better pavements. Consequently, the primary objective of this study is to evaluate the freeze-thaw durability of soils stabilized with CFA and CKD. To that end, two different types of soils, namely, Carnasaw series (fat clay) and Lomill series (fat clay) were stabilized with CFA and CKD. Specifically, the deleterious effects of F-T cycles were evaluated by conducting unconfined compressive strength (UCS) and resilient modulus $\left(\mathrm{M}_{\mathrm{r}}\right)$ tests on stabilized soil specimens.

\section{PREVIOUS STUDIES}

A review of previous studies reveals no widely accepted laboratory procedure to evaluate the freeze-thaw durability of chemically stabilized soils. Guettala et al. (2002) examined F-T durability of earth blocks with the increase of sand content. Specimens were subjected to F-T cycles in accordance with the ASTM D 560 test method. F-T tests were carried out by placing the soil specimens on an absorbent water saturated pad at a temperature of $-9.4^{\circ} \mathrm{F}\left(-23^{\circ} \mathrm{C}\right)$ for a period of 24 hours and then thawed in a moist environment at $70^{\circ} \mathrm{F}\left(21^{\circ} \mathrm{C}\right)$. It was observed that by increasing the sand content to $30 \%$, the weight loss reaches a plateau and stops decreasing.

In a comparative study by Parsons and Milburn (2003), the durability of soils treated with different additives, namely, lime, CFA, Portland cement and enzymatic stabilizer were evaluated. After compaction of the soil-additive mix, the samples were cured for 7 days in a humidity room and then subjected to a series of F-T cycles. The cement-treated soils had the least weight loss in F-T testing, while CFA-treated soils had lower weight losses in F-T testing than the lime-treated soils.

Arora and Aydilek (2005) conducted F-T tests on silty sand (SM) stabilized with 40\% class F fly ash in combination with cement or lime. It was found that the strength of specimens stabilized with class $\mathrm{F}$ fly ash and cement increased with an increasing number of F-T cycles. The increase in strength was more enhanced for mixtures that contained 7\% cement than for mixtures with 4 and $5 \%$ cement. Also, limestabilized specimens survived during F-T cycles but their strengths decreased with an increasing number of F-T cycles.

Chen et al. (2010) investigated the influence of F-T cycles on soils stabilized with lime and liquid stabilizer. It was found that the compressive strength of stabilized soils decreases with an increase in the number of F-T cycles. Also, results demonstrated that the stabilized soils have better impermeability and F-T resistance compared to raw soils which helps by preventing settlement, frost boil and other damages in seasonally frozen regions.

Shafique et al. (2010) studied the effect of F-T cycles on the long-term performance of fly ash stabilized fine-grained soils. A total of two types of clay soils were stabilized with CFA. Furthermore, ten different sets from each of the following fly ash content groups $(0 \%, 5 \%, 10 \%, 20 \%)$ were prepared at an optimum moisture content and maximum dry density. One set of specimens were tested for plasticity, unconfined compression and vertical swell after 7 days of curing. The other nine sets of specimens were used for simulating weathering actions: three sets with tap water and three sets with saline water were subjected to 12 F-T cycles. The fly ash stabilization showed a decrease in plasticity, vertical swell and increase in unconfined compressive strength values with increasing fly ash content. The effect of F-T cycles showed no significant change in plasticity and swelling values and $20-40 \%$ decrease in strength values. However, 
the strength of Class C fly ash soils after the F-T cycles was at least three times higher than soil without fly ash.

In a recent study, Shibi and Kamei (2014) evaluated the effect of various combinations of recycled bassanite and coal ash on cement-stabilized soft clay soil by conducting unconfined compressive strength and volume change tests after F-T cycles. Soil samples were prepared by mixing different amount of bassanite $(0 \%, 5 \%, 10 \%, 20 \%)$, coal ash $(0 \%, 10 \%, 20 \%)$ and 5\% cement. After 28 days of curing, samples were subjected to five F-T cycles and tested for compressive strength. The results showed that bassanite and coal ash significantly increase the durability and strength of the stabilized soil whereas coal ash alone has a negative effect on strength improvement. The first two F-T cycles significantly decreased the unconfined compressive strength. Specifically, the durability of stabilized soil retained $65-85 \%$ of its strength while soil without any additives retained only $50 \%$ of its compressive strength.

In another recent study, Bandara et al. (2015) conducted laboratory and field freeze-thaw testing of samples stabilized with CKD, CFA, lime kiln dust and concrete fines. Sokaed unconfined compressive strength tests were conducted to simulate the long-term strength gain or loss with time. The results showed that only CKD can be successfuly used as a subgrade stabilizing agent for the tested soil type. Further laboratory samples were subjected to different number of F-T cycles in a laboratory freezer and the unconfined compressive strength of those samples were measured after $0,1,3,7$ and 12 cycles. Results showed significant strength loss of CKD stabilized soils after 12 F-T cycles. Field investigation of a pavement subgrade stabilized with CKD was also conducted during this study and showed retained subgrade strength after 6 years of service life.

\section{MATERIALS AND TEST PROCEDURE}

\section{Materials and Test Procedures}

The soils used in this study belong to Carnasaw and Lomill series soils and are classified as CH (fat clay) in accordance with the Unified Soil Classification System (USCS). A summary of soil properties is presented in Table 1. A total of two cementitious additives, namely, CFA and CKD were used in this study. The CFA was produced in a coal-fired electric utility plant, American Electric Power (AEP), located in Muskogee, Oklahoma. The CKD used was provided by Lafarge North America, in Tulsa, Oklahoma. CKD is an industrial waste collected during the production of Portland cement. The properties of additives are presented in Table 2. The differences between the chemical composition and physical properties among the selected additives are clearly evident.

Table 1. Testing Designation and Soil Properties

\begin{tabular}{|l|l|c|l|}
\hline Methods & Parameter/Units & Carnasaw & Lomill \\
\hline ASTM D 2487 & USCS Symbol & CH & CH \\
\hline AASHTO M 145 & AASHTO Designation & A-7-5 & A-7-6 \\
\hline ASTM D 2487 & USCS Name & Fat clay & Fat clay \\
\hline ASTM D 2487 & \% finer than 0.075 mm & 92 & 93 \\
\hline ASTM D 4318 & Liquid limit & 58 & 54 \\
\hline ASTM D 4318 & Plastic limit & 29 & 19 \\
\hline ASTM D 4318 & Plasticity index & 29 & 35 \\
\hline ASTM D 854 & Specific Gravity & 2.62 & 2.68 \\
\hline
\end{tabular}




\section{Table 2. Chemical and Physical Properties of Additives}

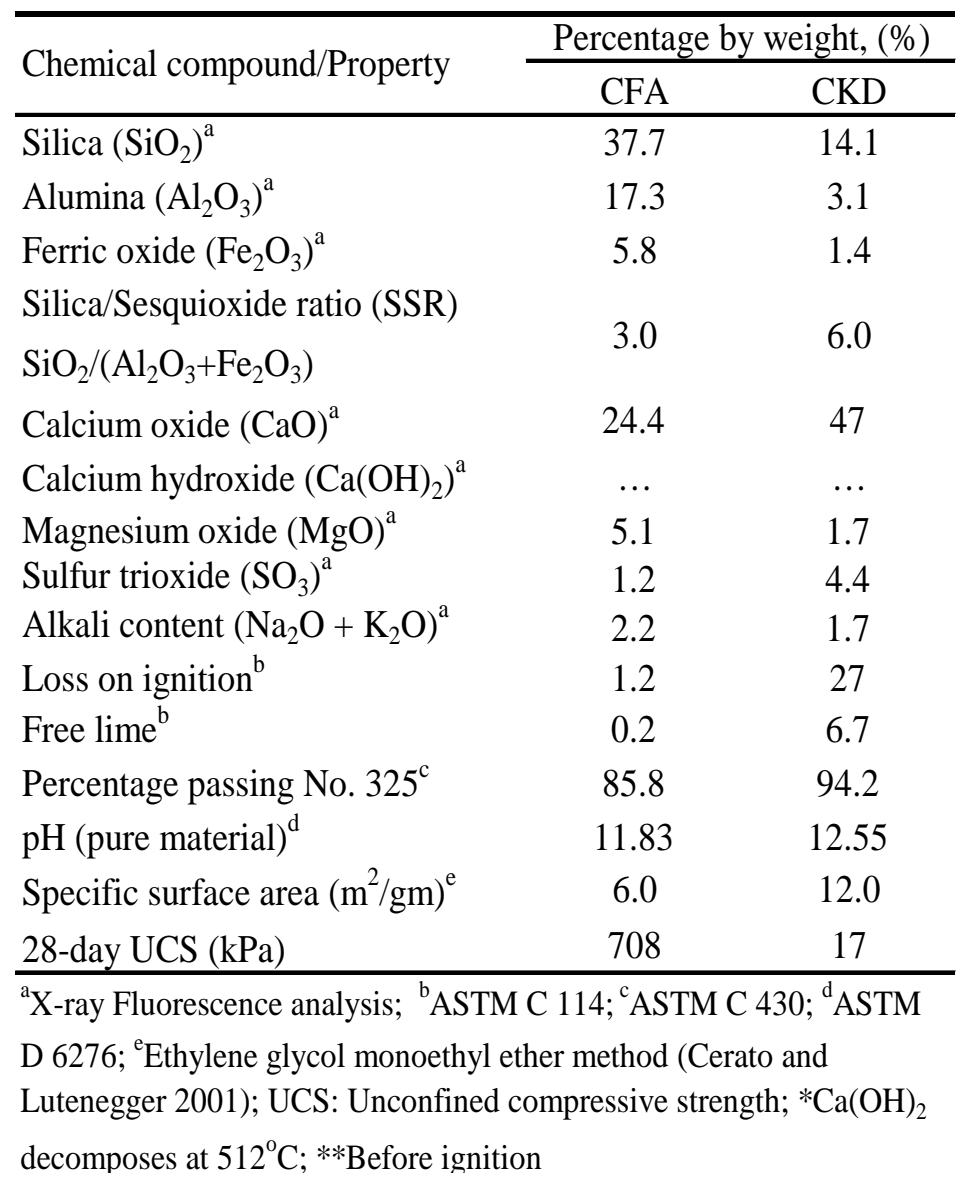

\section{Specimen Preparation}

Specimens were prepared by adding a specific amount of additive, namely $10 \%$ CFA or $10 \%$ CKD to the raw soil. The amount of additive was based on the dry weight of soil. The additive and soil were mixed manually to uniformity. After the blending process, a desired amount of water was added based on the optimum moisture content (OMC), as determined in accordance with the ASTM D 698 test method. Then, the mixture was compacted using two different cylindrical molds depending on the testing method adopted. Specimens tested for $\mathrm{M}_{\mathrm{r}}$ had a diameter of $101.6 \mathrm{~mm}$ (4.0 in) and a height of $203.2 \mathrm{~mm}$ (8.0 in.), whereas the specimens tested for UCS after conventional F-T cycle had a diameter of $33.02 \mathrm{~mm}$ (1.3 in.) and a height of $71.12 \mathrm{~mm}$ (2.8 in.). A total of two replicates were prepared for each specific test. After compaction, specimens were cured for 7 days in a humidity room having a temperature of $23.0 \pm 1.7^{\circ} \mathrm{C}$ $\left(73.4 \pm 3.1^{\circ} \mathrm{F}\right)$ and a relative humidity of approximately $96 \%$. The specimens were then subjected to the UCS or $\mathrm{M}_{\mathrm{r}}$ tests following a predetermined schedule.

\section{Conventional Freeze-Thaw Test (Unconfined Compressive Strength)}

The freeze-thaw (F-T) test was performed in accordance with the procedures outlined in the ASTM D 560 test method. A total of two replicates were prepared for each combination and then subjected to $0,1,4,8$ 
and 12 F-T cycles after 7 days of curing. Each F-T cycle consisted of freezing for 24 hours at a temperature not warmer than $-23.3^{\circ} \mathrm{C}\left(-10^{\circ} \mathrm{F}\right)$ and thawing for 23 hours at $21.1^{\circ} \mathrm{C}\left(70^{\circ} \mathrm{F}\right)$ and $100 \%$ relative humidity. Free potable water was made available to the porous plates under the specimens to permit the specimens to absorb water through capillary action during the thawing period. After the completion of appropriate F-T cycle, unconfined compressive strength (UCS) tests were conducted by loading the specimens in a displacement control mode at a strain rate of $1 \%$ per minute.

\section{Conventional Freeze-Thaw Test (Resilient Modulus)}

The 7-day cured specimens were subjected to F-T cycles by using similar procedure as described earlier. After the completion of the appropriate F-T cycle, the $\mathrm{M}_{\mathrm{r}}$ tests were performed in accordance with the AASHTO T 307 test method. The test procedure consisted of applying 15 stress sequences using a cyclic haversine-shaped load pulse with a duration of 0.1 seconds and a rest period of 0.9 seconds. For each sequence, the applied load and the vertical displacement for the last five cycles were recorded and used to determine the $\mathrm{M}_{\mathrm{r}}$. A 2.22-kN (500-lb) load cell was used to apply the required load level. Two linear variable differential transformers (LVDTs) were used to measure the resilient vertical deformation. These LVDTs were attached to two aluminum clamps that were mounted on the specimen at a distance of approximately $50.8 \mathrm{~mm}$ (2.0 in) from both ends of the specimen. The LVDTs had a maximum stroke length of $5.08 \mathrm{~mm}(0.2 \mathrm{in})$.

\section{PRESENTATION AND DISCUSSION OF RESULTS}

\section{Effect of F-T Cycles on UCS}

The individual results of the UCS tests after $0,1,4$, 8, and 12, F-T cycles are graphically illustrated in Figures 1 (a) and (b) for Carnasaw and Lomill series soil specimens, respectively. All the specimens tested in this study generally showed a reduction in the UCS values with an increase in the number of F-T cycles. For example, the UCS value of raw, 10\% CFA-, and 10\% CKD-stabilized Carnasaw series soil specimens after $4 \mathrm{~F}-\mathrm{T}$ cycles are approximately 95.5\%, 97.5\%, and 93.7\% lower than a comparable specimen with no F-T cycle. A similar qualitative trend was observed for the Lomill specimens, where the UCS values exhibited a decrease as the number of F-T cycles increased up to 12. The decrease in UCS values can be explained by a combined effect of pore structure and the increase in moisture content during the thawing portion of the cycle. An increase in moisture content during the thawing phase results in the formation of ice lenses within the void space of the specimens in the freezing phase; formation of ice lenses distorts the structure of raw and stabilized specimens (Solanki, 2010). On the other hand, a higher density of stabilized soil specimens indicates a fine pore structure. The capillary force exerted on a pore wall depends on the pore size: the smaller the pore, the higher the suction force. As water enters and exits the pores, it can generate considerable pressure and degrade the surrounding material (Prusinski and Bhattacharja, 1999). It is also clear from Figures 1 (a) and (b) that the decrease in UCS from F-T cycle 0 to 1 is higher than the decrease in UCS between the other F-T cycles. For example, UCS values of 10\% CFA-stabilized Carnasaw soil specimens decreased by approximately $96.9 \%$ between F-T cycle 0 and 1 , 20.4\% between F-T cycle 1 and 4, 20.6\% between F-T cycle 4 and 8, and 51\% between F-T cycle 8 and 12. 


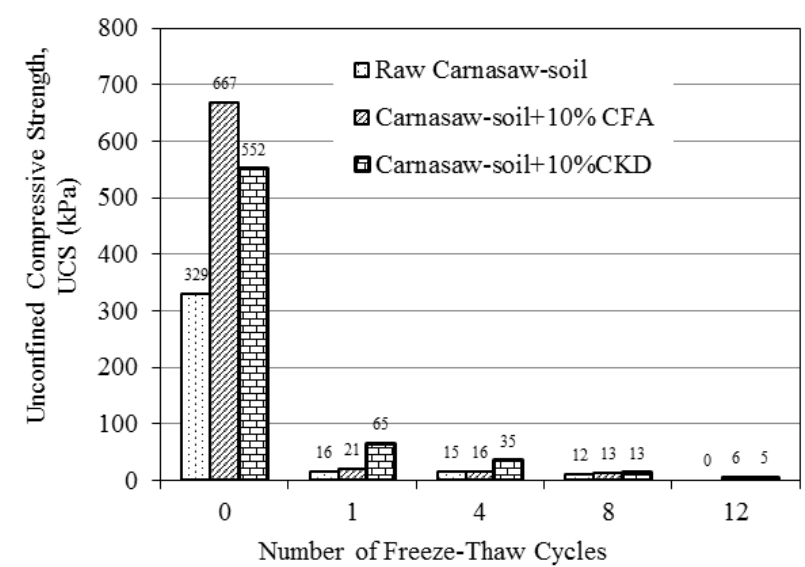

(a)

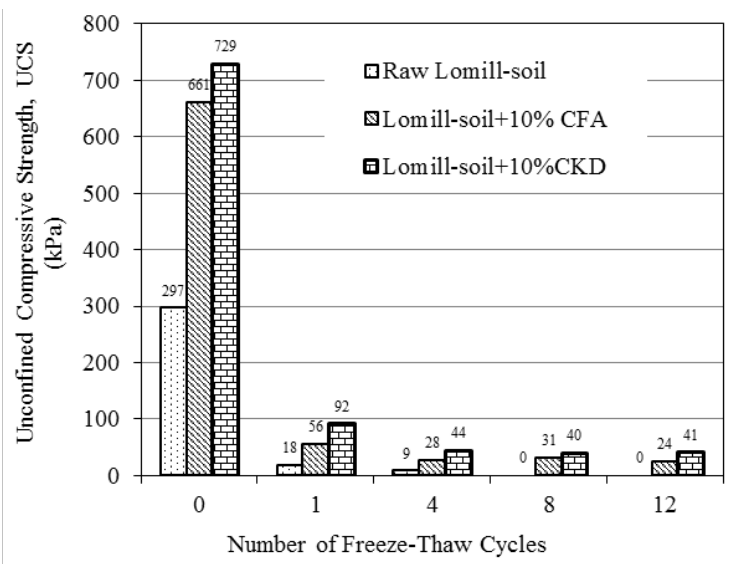

(b)

Figure 1. UCS Values of Stabilized (a) Carnasaw Soil and (b) Lomill Soil After F-T Cycles

The effect of F-T action on UCS values varies from one soil-additive mixture to another, as shown in Figures 1 (a) and (b). It is evident that specimens stabilized with 10\% CKD provided more resistance towards F-T as compared to corresponding specimens stabilized with 10\% CFA. For example, the average UCS value of $10 \%$ CKD-stabilized Carnasaw soil specimens subjected to $1 \mathrm{~F}$-T cycle is $605 \mathrm{kPa}$, as compared to $271 \mathrm{kPa}$ for $10 \%$ CFA-stabilized specimens. Similarly, the average UCS value of $10 \%$ CKD-stabilized Lomill soil specimens subjected to $1 \mathrm{~F}$-T cycle is $92 \mathrm{kPa}$, as compared to $56 \mathrm{kPa}$ for $10 \%$ CFA-stabilized specimens. Figures 2 (a) through (e) show photographic views of raw and stabilized specimens of Carnasaw and Lomill soil specimens. It is clear from Figures 2 (a) through (e) that raw soil specimens show more degradation than the corresponding stabilized Carnasaw and Lomill soil specimens.

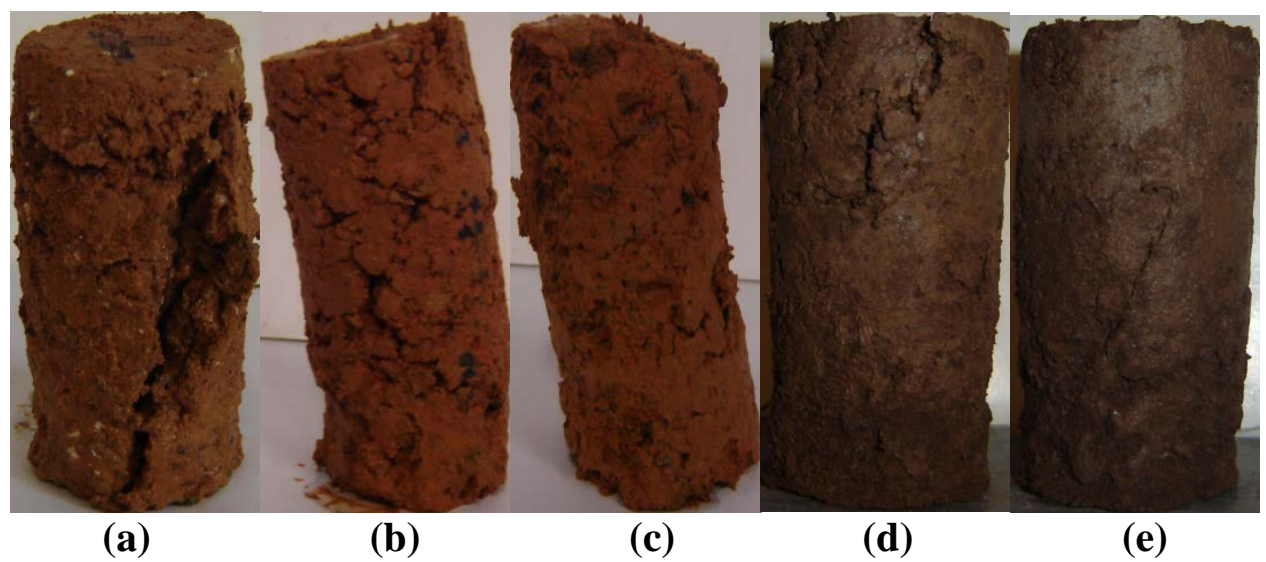

Figure 2. Harvard Miniature Specimens at the End of 12 F-T Cycles After UCS Test (a) Raw, (b) CFA-stabilized, (c) CKD-stabilized Carnasaw, (d) CFA-stabilized, and (e) CKDstabilized Lomill

\section{Effect of F-T Cycles on $M_{r}$}

Resilient modulus tests were conducted on the soil specimens at the end of only 0 and 1 F-T cycles; no specimen survived beyond 2 F-T cycles. For comparison, $M_{r}$ values at a particular stress level $\left(\sigma_{d}=5.4\right.$ psi, $\sigma_{3}=2$ psi) are graphically presented in Figures 3 (a) and (b) for Carnasaw and Lomill series soils, 
respectively. The selected stress level represent the stress state that a subgrade layer encounters under traffic loading (NCHRP, 2003). In general, it is clear that both raw and stabilized specimens of Carnasaw and Lomill soils showed a reduction in $\mathrm{M}_{\mathrm{r}}$ values due to the application of F-T cycles. For example, the application of 1 F-T cycle decreased the $\mathrm{M}_{\mathrm{r}}$ values of raw, 10\% CFA-, and 10\% CKD-stabilized Port series soil specimens by approximately $100 \%, 85 \%$, and $89 \%$, respectively. Such reductions in $\mathrm{M}_{\mathrm{r}}$ values could be explained by using similar reasons as discussed in previous section.

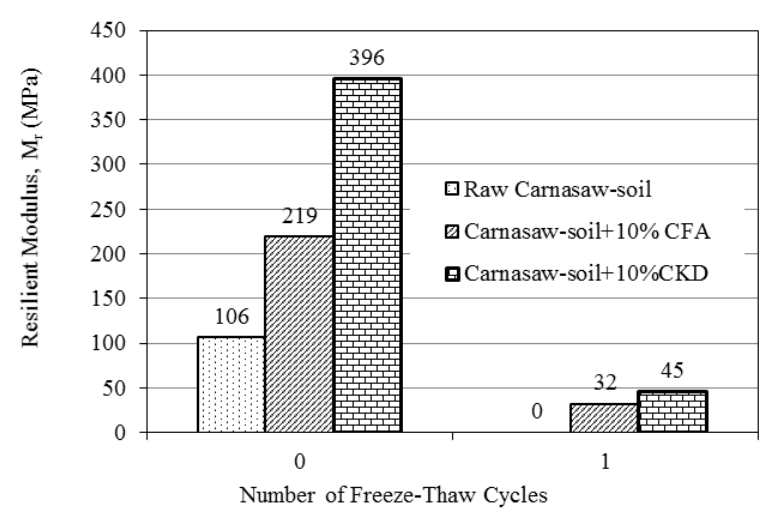

(a)

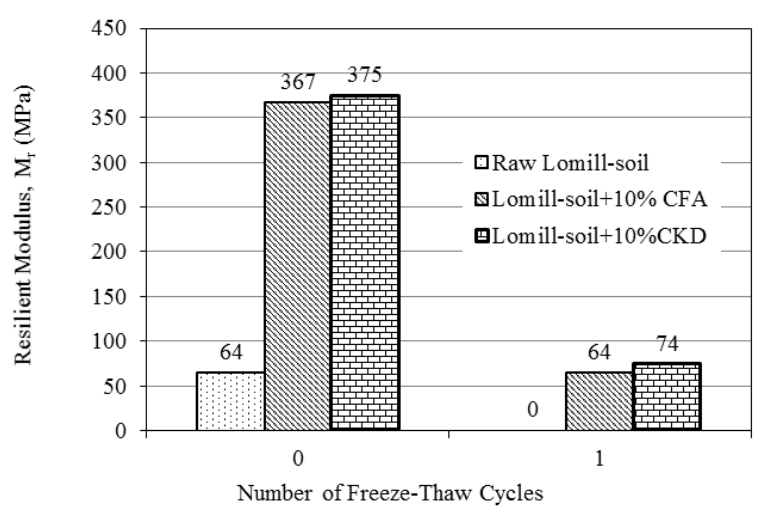

(b)

\section{Figure 3. Mr Values of Stabilized (a) Carnasaw Soil and (b) Lomill Soil After Freeze-Thaw Cycles}

It is also evident from Figures 3 (a) and (b) that both soils provided the highest $\mathrm{M}_{\mathrm{r}}$ values with 10\% CKD after $1 \mathrm{~F}-\mathrm{T}$ cycle. For example, raw, 10\% CFA, and 10\% CKD provided $\mathrm{M}_{\mathrm{r}}$ values of Carnasaw soil ranging between $23-50 \mathrm{MPa}, 30-76 \mathrm{MPa}$, and $41-85 \mathrm{MPa}$ at the end of $1 \mathrm{~F}-\mathrm{T}$ cycle. The Lomill series soil provided a similar range of $\mathrm{M}_{\mathrm{r}}$ values at the end of $1 \mathrm{~F}-\mathrm{T}$ cycle with $10 \%$ CKD (73 - 107 $\mathrm{MPa}), 10 \%$ CFA (63 - $92 \mathrm{MPa})$ and raw (12 - $23 \mathrm{MPa})$ which are the lowest $\mathrm{M}_{\mathrm{r}}$ values. Similar reductions in $\mathrm{M}_{\mathrm{r}}$ values due to the application of F-T cycles were reported by Khoury (2007) for base course materials stabilized with CKD and CFA. To the author's knowledge, no study is available in the open literature indicating the effect of F-T cycles on $\mathrm{M}_{\mathrm{r}}$ values of stabilized subgrade soils.

\section{Effect of Size on F-T Durability}

To study the effect of size on the F-T durability of the specimens, selected Carnasaw series soil specimens were tested for UCS at the end of the F-T cycles. A total of eight cylindrical specimens having a diameter of $101.6 \mathrm{~mm}$ (4.0 in) and a height of $203.2 \mathrm{~mm}$ (8.0 in.) were prepared in this study in accordance with method discussed in specimen preparation section. These eight specimens included two replicates for each soil-additive mix, namely raw Carnasaw soil, Carnasaw soil with $10 \%$ CFA, and Carnasaw soil with 10\% CKD. After 7 days of curing, one replicate was tested for UCS before any F-T cycle, whereas the other replicate was tested for UCS after 1 F-T cycle in accordance with method discussed in Materials and Test Procedure section. A summary of UCS values before and after $1 \mathrm{~F}-\mathrm{T}$ cycle of raw soil, 10\% CFA-, and 10\% CKD-stabilized specimens is presented in Figure 4. For comparison purpose, the UCS values of corresponding Harvard miniature specimens (31 mm x $71 \mathrm{~m}$ ) are also presented in same figures. 


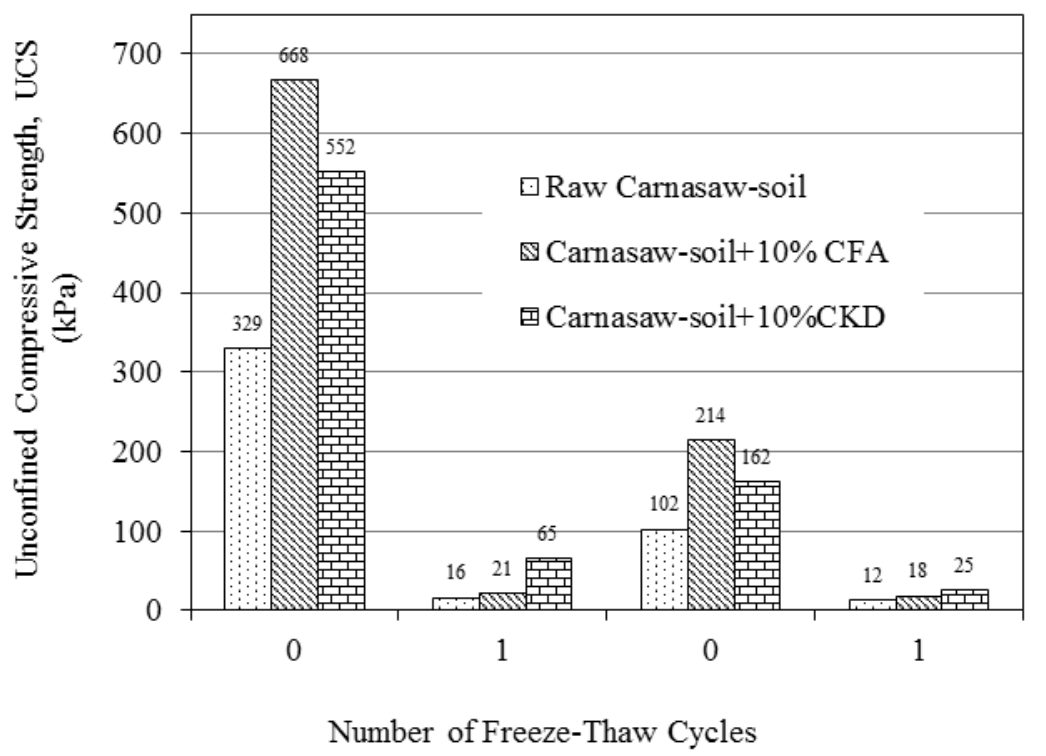

\section{Figure 4. Effect of Different Sizes of Carnasaw Soil Specimens on UCS Values at the End of F-T Cycles}

It is clear from Figure 4 that the UCS values of specimens having a bigger size (101.6 $\mathrm{mm}$ x $203.2 \mathrm{~mm})$ is lower than the UCS values of corresponding specimens having a smaller size (Harvard miniature specimens, $31 \mathrm{~mm} \times 71 \mathrm{~mm}$ ). For example, the UCS values of $101.6 \mathrm{~mm}$ x $203.2 \mathrm{~mm}$ specimens is approximately $22 \%, 13 \%$, and $61 \%$ lower than the UCS values of corresponding smaller specimens of Carnasaw soil stabilized with $0 \%, 10 \%$ CFA-, and 10\% CKD, respectively.

\section{CONCLUSION}

A laboratory study was conducted to determine the F-T durability of two soils stabilized with CFA and CKD. Specimens were prepared by compacting soil-additive mixture containing $10 \%$ CFA or $10 \%$ CKD. Additionally, raw soil specimens were compacted without using any additive. Then, specimens were cured for 7 days and subjected to F-T cycles. Small Harvard miniature specimens (31 mm x $71 \mathrm{~mm}$ ) were tested for UCS at the end of 0, 1, 4, 8 and 12 F-T cycles. Additionally, cylindrical specimens (101.6 mm x $203.2 \mathrm{~mm}$ ) were tested for $\mathrm{M}_{\mathrm{r}}$ at the end of 0 and $1 \mathrm{~F}-\mathrm{T}$ cycles. Further, selected specimens were tested to study the effect of size on F-T durability of specimens.

The results show that UCS values of all the specimens decreases with increase in the number of F-T cycles. Such a decrease could be explained by the increase in moisture absorbed by specimens during the thawing portion of the cycle and pore structure of the stabilized specimens. The level of reduction in the UCS values was influenced by the type of soil and type and amount of stabilizing agent. A major loss in strength was observed between 0 and 1 F-T cycle. The $M_{r}$ values of both raw and stabilized soil specimens were found to decrease with an increase in the number of F-T cycles. None of the $\mathrm{M}_{\mathrm{r}}$ specimens survived more than 2 F-T cycles. Overall, soil specimens stabilized with $10 \%$ CKD offered maximum resistance towards F-T cycles. Furthermore, the UCS values of specimens having bigger size was found to be lower than the UCS values of corresponding specimens having smaller size. 


\section{REFERENCES}

AASHTO (2004). "Guide for Mechanistic-Empirical Design of New and Rehabilitated Pavement Structures," Final Report prepared for National Cooperative Highway Research Program (NCHRP) 1-37A, Transportation Research Board, National Research Council, Washington DC.

AASHTO (2009). Rough Road Ahead: Fix Them Now or Pay For It Later, Transportation Research Board, National Research Council, Washington, DC.

Arora, S and Aydilek, A.H. (2005). “Class F Fly-Ash-Amended Soils as Highway Base Materials.” ASCE Journal of Materials in Civil Engineering, 17, 6, 640 - 649.

Bandara, N., Binoy, T. H. and Aboujrad, H. S. (2015). "Freeze-Thaw Durability of Subgrades Stabilized with Recycled Materials," $16^{\text {th }}$ International Conference on Cold Regions Engineering, July 19-22, Salt Lake City, Utah, pp. 135 - 145.

Bin-Shafique, S., Rahman, K., Yaykiran, M., and Azfar, I. (2010), “The long-term performance of two fly ash stabilized fine-grained soil subbases,” Resources, Conservation and Recycling, Vol. 59, pp. 662672.

Chen, Y. et al. (2010). "Test Study on Road Performance of Soils Stabilized by Liquid Stabilizer in Seasonally Frozen Regions.” Integrated Transportation Systems - Green Intelligent Reliable, 32453252.

Guettala, A., Houari, H., Mezghiche, B., and Chebili, R. (2002). "Durability of Lime Stabilized Earth Blocks.” Courrier Du Savoir, No02, 61-66.

Karthik, S., Ashok kumar, E., Gowtham, P., Elango, G., Gokul, D., Thangaraj, S. (2014), "Soil Stabilization By Using Fly Ash,” IOSR Journal of Mechanical and Civil Engineering, Vol. 10, pp. 2026.

Khoury, N., and Zaman, M. M. (2007). "Durability of Stabilized Base Courses Subjected to Wet-Dry Cycles,” International Journal of Pavement Engineering, Vol. 8, No. 4, 265-276.

Little, D. N. and Nair, S. (2009). "Recommended Practice for Stabilization of Subgrade Soils and Base Materials,” NCHRP Web-Only Document 144, Contractor's Final Task Report for NCHRP Project 20-07, Transportation Research Board, National Research Council, Washington, DC.

National Cooperative Highway Research Program (NCHRP) (2003). "Harmonized Test Methods for Laboratory Test Methods for Laboratory Determination of Resilient Modulus for Flexible Pavement Design,” Project No. 1-28 A, Washington, DC.

Parsons, R. L., and Milburn, J. P. (2003). “Engineering Behavior of Stabilized Soils,” Transportation Research Record: Journal of the Transportation Research Board, Vol. 1837, $20-29$.

Prusinski, J.R., Bhattacharia, S. (1999). Effectivenes of Portland cement and lime in stabilizing clay soils, Transportation Research Record, 1632, 215 - 227.

Shibi, T., Kamei, T. (2014), "Effect of freeze-thaw cycles on the strength and physical properties of cement-stabilised soil containing recycled bassanite and coal ash," Cold Regions Science and Technology, Vol. 106-107, pp. 36-45.

Solanki, P., Zaman, M., and Dean, J. (2010). "Resilient Modulus of clay Subgrades Stabilized with Lime, Class C Fly Ash and Cement Kiln Dust for Pavement Design,” Transportation Research Board Annual Meeting 2010, Paper \#10-1031. 
TRIP (2015), Bumpy Road Ahead: America's Roughest Rides and Strategies to Make our Roads Smoother, http://www.tripnet.org/docs/Urban_Roads_TRIP_Report_July_2015.pdf, Accessed December 14, 2015.

Wen, H., Muhunthan, B., Wang, J., Li, X., Edil, T. and Tinjum, J. M. (2014). "Characterization of Cementitiously Stabilized Layers for Use in Pavement Design and Analysis," National Cooperative Highway Research Program (NCHRP) Report No. 789, Transportation Research Board, Washington, DC. 